\title{
Study of histopathological pattern of endometrium in abnormal uterine bleeding and its management
}

\author{
Alpana Singh*, P.V. Ramana Bai \\ Department of Obstetrics \& Gynaecology, Malla Reddy Institute Of Medical Sciences, Hyderabad, Telangana, India
}

Received: 12 December 2015

Accepted: 04 January 2016

*Correspondence:

Dr. Alpana Singh,

E-mail: dralpanasingh21@gmail.com

Copyright: $\odot$ the author(s), publisher and licensee Medip Academy. This is an open-access article distributed under the terms of the Creative Commons Attribution Non-Commercial License, which permits unrestricted non-commercial use, distribution, and reproduction in any medium, provided the original work is properly cited.

\begin{abstract}
Background: Abnormal uterine bleeding is one of the most common and challenging problems presenting as an enigma to the gynecologist regardless of the age of the women. Histopathological evaluation of endometrium plays a significant and pivotal role in the diagnosis and management of endometrial causes of Abnormal Uterine Bleeding. The main aim was to study the frequency of different histopathological patterns of endometrium in patients with abnormal uterine bleeding across different age groups, know the endometrial causes of abnormal uterine bleeding and its managements.

Methods: This study was conducted on 300 patients from March 2014 to February 2015 in the department of Obstetrics and Gynaecology in a reputed teaching hospital and research centre in South India. Demographic indices were collected and recorded. Endometrial samples were sent for histopathological examinations and different endometrial patterns were noted.

Results: Abnormal Uterine Bleeding (AUB) presented mostly in the 41-50 years age spectrum (48.6\%) and most of the patients were multipara. The main presenting complaint among our patients was menorrhagia (42\%) followed by polymenorrhagia (15\%), menometrorrhagia (10.6\%), continuous vaginal bleeding (9.6\%), Polymenorrhea $(9.3 \%)$, postmenopausal bleeding (8.6\%) and metrorrhagia (4.6\%).The commonest histopathological pattern in abnormal uterine bleeding was normal physiological phases of menstrual cycle - proliferative and secretary endometrium $(37 \%$ and $30 \%$ respectively). Endometrial hyperplasia was the most common endometrial pathology observed (22.6\%).

Conclusions: Endometrial evaluation in abnormal uterine bleeding in different age groups helps in the management, especially in the perimenopausal and postmenopausal age groups to rule out premalignant conditions and malignancy.
\end{abstract}

Keywords: Abnormal uterine bleeding, Multipara, Menorrhagia, Endometrial carcinoma

\section{INTRODUCTION}

Abnormal Uterine Bleeding (AUB) is a common condition affecting the women of reproductive age that has a significant social and economic impact. ${ }^{1}$ It has a negative impact on women's health and wellbeing including anaemia, absenteeism and social embarrassment. It is considered one of the most common and challenging problems presenting to the gynaecologist regardless of age. ${ }^{2}$ It occurs in $9-14 \%$ of women between menarche and menopause, significantly impacting quality of life and imposing financial burden. ${ }^{3}$

Abnormal uterine bleeding is defined as bleeding from the uterine corpus that is abnormal in volume, regularity and / or timing and has been present for majority of the past 6 months. ${ }^{4}$ It includes menorrhagia, metrorrhagia menometrorrhagia, polymenorrhagia, polymenorrhea, continuous vaginal bleeding and intermenstrual bleeding. There are both organic and non-organic causes of abnormal uterine bleeding. 
The causes of Abnormal Uterine Bleeding can be categorized into two broad categories: I - Organic causes: Genital tract infections, tumors (benign or malignant), adenomyosis, iatrogenic and systemic disorders.

\section{Dysfunctional uterine bleeding (DUB)}

The causes of abnormal uterine bleeding have been categorized by the International Federation of Gynecology and Obstetrics (FIGO) into a new classification system (PALM-COEIN) which includes nine categories. First four entities have visually objective structural etiologies (PALM: Polyp, Adenomyosis, Leiomyoma, and Malignancy and hyperplasia).The second four are unrelated to structural abnormalities (COEI: Coagulopathy, Ovulatory dysfunction, Endometrial and Iatrogenic), and the final category is for entities that are Not yet classified $(\mathrm{N}){ }^{4}$

AUB can present in many patterns and can be evaluated by histopathology which remains the diagnostic standard for the clinical diagnosis of endometrial pathology and its management. This study was done to determine the histopathological pattern of endometrium in women across different age groups presenting with AUB and their management.

\section{METHODS}

This was a prospective analytical study. 300 patients in the Department of Obstetrics and Gynaecology, in a reputed teaching hospital and research centre in South India, from March 2014 to February 2015. Patients aged more than 18 years attending the Gynaecology OPD with endometrial aetiology of abnormal uterine bleeding were selected based on clinical details. Those with known causes like leiomyoma, adenomyosis, polyp, endometriosis, pelvic inflammatory disease, cervical pathology, thyroid disorder and coagulation disorders were excluded from the study. Patients were categorized into groups according to age; I 21-30 years; II 31-40 years, III 41-50 years and IV $>50$ years. After detailed history taking and thorough examination, base line investigations and pelvic ultrasound (GEP-6 using convex probe, $3.5-5 \mathrm{~Hz}$ ) were performed. All the selected patients underwent endometrial biopsy and endometrial samples were sent in $10 \%$ formalin for histopathological examinations. Patients were managed either conservatively or surgically depending on their age, severity of bleeding and histopathological findings. Demographic data, patients complete laboratory reports, treatment strategy and outcome were collected, documented and analyzed.

\section{Statistical analysis}

Statistical testing was conducted with the Statistical Package for the Social Science System (SPSS). Categorical variables are presented as absolute numbers and percentage. Nominal categorical data between the groups were compared using chi2 goodness-to-fit test. The $\alpha$ level was set as $p$ value less than 0.05 .

\section{RESULTS}

A total of 300 patients were enrolled in this study. Age of the patients with AUB ranged from 21 to 67 years in our study. Patients were categorized into four groups according to their age. Group -1 comprises of patients with age 21-30yrs; group -2 patients with age 31-40years, group-3 patients with 41-50years and group-4 patients with age $>50$ years (Table 1). Maximum frequency of AUB was observed in 41-50 years age spectrum (48.6\%) followed by $31-40$ years $(39.6 \%)$ while the minimum was seen in 21-30 years i.e.5.3\%.

Table 1: Distribution of AUB in different age groups.

\begin{tabular}{|clll|}
\hline Groups & Age in years & $\begin{array}{l}\text { No. of } \\
\text { patients }\end{array}$ & Percentage \\
\hline 1 & $\leq 30$ & 16 & $5.3 \%$ \\
\hline 2 & $31-40$ & 109 & $36.3 \%$ \\
\hline 3 & $41-50$ & 146 & $48.6 \%$ \\
\hline 4 & $>50$ & 29 & $9.6 \%$ \\
\hline
\end{tabular}

Incidence of AUB was noted to increase with parity. As shown in Table 2 most of the patients were having parity $\geq 3(n=117,39 \%)$ while $106(35.3 \%)$ patients were Para 2, 53(17.6\%) were Para 1 and 24(8\%) were nullipara.

Table 2: Distribution of AUB according to parity.

\begin{tabular}{|lllllc|}
\hline Parity & $\begin{array}{l}<0 \\
\text { years }\end{array}$ & $\begin{array}{l}31-40 \\
\text { years }\end{array}$ & $\begin{array}{l}41-50 \\
\text { years }\end{array}$ & $\begin{array}{l}>50 \\
\text { years }\end{array}$ & Total \\
\hline 0 & 6 & 4 & 3 & 11 & $24(8 \%)$ \\
\hline 1 & 4 & 21 & 23 & 5 & $53(17.6 \%)$ \\
\hline 2 & 3 & 40 & 57 & 6 & $106(35.3 \%)$ \\
\hline$\geq 3$ & 3 & 44 & 63 & 7 & $117(39 \%)$ \\
\hline Total & 16 & 109 & 146 & 29 & 300 \\
\hline
\end{tabular}

Table 3 shows the main presenting complaint in the patients in a decreasing order: menorrhagia (42\%), polymenorrhagia $(15 \%)$, menometrorrhagia (10.6\%), continuous vaginal bleeding $(9.6 \%)$, polymenorrhea (9.3\%), postmenopausal bleeding (8.6\%) and metrorrhagia (4.6\%). An age specific comparative analysis of the clinical presentation revealed that menorrhagia was the commonest complaint in the 31-40 years and $41-50$ years age groups $(47.9 \%$ and $44.9 \%$ of the cases respectively). Post-menopausal bleeding was the most common complaint in $>50$ years $(68.9 \%)$ while in age group <30years, menorrhagia (43.7\%) and polymenorrhea $(25 \%)$, were common complains.

Table 4 shows distribution of different endometrial patterns in different age groups. The commonest 
histopathological pattern in abnormal uterine bleeding was normal physiological phases of menstrual cycle proliferative and secretory endometrium seen in 111 $(37 \%)$ and $90(30 \%)$ cases respectively. Disordered proliferative endometrium was observed in $17(5.6 \%)$ cases. Endometrial hyperplasia was the most common endometrial pathology observed in $68(22.6 \%)$ cases, out of which 47 (15.6\%) were simple hyperplasia, 10 (3.3\%) were complex hyperplasia and $8(2.6 \%)$ were showing complex hyperplasia with atypia. Endometrial carcinoma was found only in $3(1 \%)$ cases. Other types of histopathological findings were chronic endometritis and atrophic endometrium $(1.6 \%$ and $3 \%$ of cases respectively).

Table 3: Age wise distribution of pattern of bleeding.

\begin{tabular}{|llllll|}
\hline Pattern of bleeding & $<30$ years & $\mathbf{3 1 - 4 0}$ years & $\mathbf{4 1 - 5 0}$ years & $>\mathbf{5 0}$ years & Total \\
\hline Menorrhagia & 7 & 49 & 70 & 0 & $126(42 \%)$ \\
\hline Menometrorrhagia & 0 & 11 & 21 & 0 & $32(10.6 \%)$ \\
\hline Postmenopausal bleeding & 0 & 0 & 6 & 20 & $26(8.6 \%)$ \\
\hline Continuous bleeding & 3 & 9 & 15 & 2 & $29(9.6 \%)$ \\
\hline Polymenorrhagia & 2 & 21 & 22 & 0 & $45(15 \%)$ \\
\hline Metrorrhagia & 0 & 0 & 7 & 7 & $14(4.6 \%)$ \\
\hline Polymenorrhea & 4 & 19 & 5 & 0 & $28(9.3 \%)$ \\
\hline Total & 16 & 109 & 146 & 29 & \\
\hline
\end{tabular}

Table 4: Distribution of different endometrial patterns in different age groups.

\begin{tabular}{|llllll|}
\hline Endometrial histology & $<30$ years & $\mathbf{3 1 - 4 0}$ years & $\mathbf{4 1 - 5 0}$ years & $>\mathbf{5 0}$ years & Total \\
\hline Proliferative & 8 & 44 & 57 & 2 & $111(37 \%)$ \\
\hline Secretory & 7 & 42 & 41 & 0 & $90(30 \%)$ \\
\hline Chronic Endometritis & 1 & 4 & 0 & 0 & $5(1.6 \%)$ \\
\hline Atrophic & 0 & 0 & 5 & 4 & $9(3 \%)$ \\
\hline Disordered proliferative endometrium & 0 & 5 & 10 & 2 & $17(5.6 \%)$ \\
\hline Endometrial hyperplasia & 0 & 14 & 33 & 21 & $68(22.6 \%\}$ \\
\hline Simple & 0 & 13 & 24 & 10 & $47(15.6 \%)$ \\
\hline Complex & 0 & 1 & 5 & 4 & $10(3.3 \%)$ \\
\hline Complex with atypia & 0 & 0 & 3 & 5 & $8(2.6 \%)$ \\
\hline Endometrial carcinoma & 0 & 0 & 1 & 2 & $3(1 \%)$ \\
\hline Total & 16 & 109 & 146 & 29 & \\
\hline
\end{tabular}

Age specific comparative analysis in this study revealed that the incidence of endometrial hyperplasia and malignancy are more common in perimenopausal and postmenopausal age group.

All the cases in our study were managed either conservatively or surgically depending on the age of the patient, severity of the bleeding, histopathological findings of the patient and willingness of the patient. The conservative treatments given were tranexemic acid, oral contraceptive pills, oral progesterone and Levonorgestrelintrauterine delivery system (LNG-IUD). Surgical procedures performed were abdominal hysterectomy, vaginal hysterectomy, and total laparoscopic hysterectomy with or without oophorectomy. Table 5 shows management of AUB in different age groups.

All the patients in group 1 were treated conservatively. In group 2,75 patients $(68.8 \%)$ were treated conservatively while surgery was performed on 34 patients $(31.1 \%)$ who were having complex endometrial hyperplasia, severe degree of menorrhagia and unwilling for conservative treatment and follow up. In group 3, most of the cases $(n=116,79.4 \%)$ were managed with surgery, while conservative management was given to only 30 patients $(20.5 \%)$. Out of 29 patients in group 4, 25 were treated surgically and rest with atrophic endometrium were managed conservatively.

Table 5: Management of AUB in different age groups.

\begin{tabular}{|llll|}
\hline $\begin{array}{l}\text { Age } \\
\text { groups }\end{array}$ & $\begin{array}{l}\text { No. of } \\
\text { cases }\end{array}$ & $\begin{array}{l}\text { Conservative } \\
\text { treatment }\end{array}$ & Surgery \\
\hline 1 & 16 & $16(100 \%)$ & 0 \\
\hline 2 & 109 & $75(68.8 \%)$ & $34(31.1 \%)$ \\
\hline 3 & 146 & $30(20.5 \%)$ & $116(79.4 \%)$ \\
\hline 4 & 29 & $4(13.7 \%)$ & $25(86.2 \%)$ \\
\hline
\end{tabular}




\section{DISCUSSION}

Abnormal uterine bleeding is one of the most frequently encountered conditions in gynaecological practice world over and is defined as bleeding from the uterine corpus that is abnormal in volume, regularity and / or timing and has been present for majority of the past 6 months. ${ }^{4}$ The cause of AUB includes a wide spectrum of diseases of the reproductive system as well as non gynaecological issues. When organic causes of AUB are ruled out then a diagnosis of dysfunctional uterine bleeding (DUB) is made. In about $25 \%$ of the patients, AUB is the result of a well-defined organic abnormality. ${ }^{5}$ The diagnosis is mostly based on patient's symptom and clinical findings. In all the cases, a pelvic ultrasonography is done to correlate the clinical findings. Dilatation and curettage can be a diagnostic as well as a therapeutic procedure. ${ }^{6}$ The sensitivity of endometrial biopsy for detection of endometrial abnormalities is very high $96 \%$. $^{7}$

Our study significantly revealed that the occurrence of menstrual disorders increases with advancing age. Excessive bleeding was commonly noticed in the 41-50 years age bracket. A similar incidence was reported by Yusuf et al and Muzaffar et al in their study of endometrium. ${ }^{8,9}$ The increased incidence of abnormal uterine bleeding in this group may be due to the fact that these patients are in their climacteric period, having an ovulatory cycles. Incidence of AUB was low (9.6\%) in patients with age $>50$ years, presumably due to an early evaluation and treatment.

Incidence of AUB was noticed to be increasing with parity. $92 \%$ of patients in in our study were parous (276), while the rest (24) were nulliparous although it is statistically not significant $(\mathrm{p}=0.655)$.

Out of 3 cases of endometrial carcinoma that was observed in our study, 2 were nullipara. This indicates that nulliparity is an important risk factor for endometrial carcinoma $(\mathrm{p}=0.000167)$ as has also been reported by Wahda et al. ${ }^{10}$ This could possibly be related to the association of nulliparity with an ovulatory cycles that result in increased oestrogen exposure and lack of progesterone effect.

The commonest presenting feature was menorrhagia $(42 \%)$ followed by polymenorrhagia $(15 \%)$ but it is not significant statistically $(\mathrm{p}=0.635)$. Similar findings were validated by Moghal et al in their study named diagnostic value of endometrial curettage in abnormal uterine bleeding. ${ }^{11}$

The commonest endometrial pattern in our study was normal physiological phases of endometrium $(\mathrm{p}=6 \mathrm{E}-06$ $<0.05)$ i.e. proliferative endometrium in $37 \%$ and secretory endometrium in $30 \%$ and was comparable to the findings of a similar study done by Doraiswami $\mathrm{S}$ et al. ${ }^{12}$ The bleeding in proliferative endometrium may probably be due to an ovulatory cycles and in secretory phase due to ovulatory dysfunctional uterine bleeding. However the histopathological diagnosis does not correlate to the type of abnormal bleeding or amount of blood loss.

Endometrial hyperplasia was the commonest pathology diagnosed in our study $(22.2 \%)$ which is statistically significant $(\mathrm{p}=0)$ and compared favorably with the observation by Afgan S et al (20.6\%). ${ }^{13}$ Most of the cases were simple hyperplasia. Identification of endometrial hyperplasia is important because they are thought to be precursors of endometrial carcinoma although this is variable according to the type of hyperplasia. Endometrial carcinoma was the least common pathology in our study which was in $1 \%$ of cases and was comparable to all other studies referred to.

Age specific comparative study clearly revealed that the incidence of endometrial pathology increases with age. Disordered proliferative endometrium, endometrial hyperplasia and endometrial carcinoma are more common in perimenopausal and postmenopausal age groups.

In this study endometrial atrophy was seen in women $>40$ years old and accounted for $3 \%$ of cases of AUB. This means that atrophic endometrium occurred at or around menopause. Exact mechanism of bleeding in atrophic endometrium is not known. Anatomical vascular variations, like thin walled veins, superficial to the expanding cystic glands making the vessel vulnerable to injury, as well as abnormal local hemostatic mechanisms in the uterus have been proposed to be the underlying causes. $^{14}$

Chronic endometritis usually follows pregnancy, IUCD insertion and abortion. It may be due to viral, chlamydial, gonococcal, tuberculosis and nonspecific infection. The detection rate of chronic endometritis in our study was $1.6 \%$, all were in $<40$ years age group. No specific infection like tuberculosis was noted in any case.

Endometrial biopsy is a safe and effective diagnostic step in the evaluation of AUB after ruling out medical causes. Histopathological finding of endometrium forms the main basis of management of AUB. Young patients with normal endometrium can be treated conservatively with medical and hormonal therapy while surgical intervention is usually required in perimenopausal and postmenopausal cases with an endometrial pathology.

\section{CONCLUSIONS}

Histopathological examination of endometrial biopsy in patients with abnormal uterine bleeding showed a wide spectrum of changes ranging from normal endometrium to malignancy. Endometrial evaluation in abnormal uterine bleeding in different age groups helps in the management, especially in perimenopausal and 
postmenopausal age groups to rule out premalignant conditions and malignancy.

Funding: No funding sources

Conflict of interest: None declared

Ethical approval: The study was approved by the Institutional Ethics Committee

\section{REFERENCES}

1. The ESHRE Capri workshop group. Endometrial bleeding. Human reproduction update. 2007;13(5):421-31

2. Ozdemir S, Celik C, Gezginc K Kıreşi D, Esen H. Evaluation of endometrial thickness with transvaginal ultrasonography \& histopathology in premenopausal women with abnormal vaginal bleeding.Arch Gynecol Obstet. 2010;282(4):395-9.

3. Mary GS, Tarin AS, Patrice MW. Evaluation and management of abnormal uterine bleeding in premenopausal women. Am Fam Physician. 2012;85(1):35-43.

4. Munro MG, Critchley HO, BroderMS, Fraser IS; FIGO Working Group on Menstrual Disorders. FIGO classification system for causes of abnormal uterine bleeding in nongravid women of reproductive age. Int J Gynaecol Obstet. 2011;113(1);3-13.

5. Brenner PF. Differential diagnosis of AUB. Am J Obstet Gynecol. 1996;175:766-9.

6. Albers JR, Hull SK, Wesley RM. Abnormal uterine bleeding. Am Fam Phys. 2004;69:1915-26.

7. Litta P, Merlin F, Saccardi C, Pozzan C, Sacco G, Fracas M. Role of hysteroscopy with endometrial biopsy to rule out endometrial cancer in postmenopausal women with abnormal uterine bleeding . Marturitas. 2005;50(2):117-23.
8. Yusuf NW, Nadeem R, Yusuf AW, Rahman R. Dysfunctional uterine bleeding a retrospective clinicopathological study over 2 years. Pak J. Obstet Gynaecol. 1996;9:27-30.

9. Muzaffar M, Akhtar KA, Yasmin S, Mahmood-UrRehman, Iqbal W, Khan MA. Menstrual irregularities with excessive blood loss A clinicopathological correlation. J Pak Med Assoc. 2005;55(11):486-9.

10. Wahda MT, Manal TA, Safwan I. Histopathological Interpretation of Abnormal Uterine Bleeding After the Age of 40 Year. The Iraqi Postgraduate Medical Journal. 2010;9:274-82.

11. Moghal N. Diagnostic value of endometrial curettage in abnormal uterine bleeding- a histopathological study. J Pak Med Assoc. 1997;47:295-9.

12. Doraiswami S, Johnson $\mathrm{T}$, Rao S, Rajkumar A, Vijayaraghavan J, Panicker VK. Study of endometrial pathology in Abnormal uterine bleeding. J Obstet Gynecol India. 2011;61:426-30.

13. Afgan S, Yasmeen A. Abnormal uterine bleeding a clinicopathological study of 150 cases. Ann Pak Inst Med Sci. 2013;9(4):201-4.

14. Stead LG, Stead SM, Kaufman MS, Jeane Simmons Holmes JS, Schachel PP. First Aid For the Obstetrics and Gynaecology. Clerkship McGraw -Hill Companies, 2002:167-231.

Cite this article as: Singh A, Bai RPV. Study of histopathological pattern of endometrium in abnormal uterine bleeding and its management. Int J Reprod Contracept Obstet Gynecol 2016;5:432-6. 